\title{
Continente selvagem: o caos na Europa depois da Segunda Guerra Mundial
}

\section{Savage continent: Europe in the aftermath of World War II}

\author{
Felipe Alexandre Silva de Souza*
}

LOWE, Keith. Continente selvagem: o caos na Europa depois da Segunda Guerra Mundial. Tradução de Rachel Botelho e Paulo Schiller. $1^{\text {a }}$.ed. Rio de Janeiro: Zahar, 2017. 503p.

No dia 8 de maio de 1945, os meios diplomáticos da Europa foram tomados por uma onda de celebrações: as forças armadas da Alemanha Nazista finalmente haviam se rendido aos Aliados, colocando fim ao teatro europeu da Segunda Guerra Mundial. A partir daí, os europeus teriam se unido em harmonia para iniciar a reconstrução, superando rapidamente tanto a destruição e a escassez quanto os conflitos étnicos e políticos que impulsionaram a guerra. Esse quadro, todavia, é pouco mais do que um mito, e problematizálo é o objetivo de Continente selvagem, livro do historiador britânico Keith Lowe, lançado na Inglaterra em 2012 e no Brasil em 2017. Por intermédio de uma pesquisa de fôlego, Lowe nos mostra que a narrativa idílica de uma Europa redimida escamoteia uma realidade pouco conhecida de colapso institucional, caos, miséria, fome, criminalidade, vinganças coletivas, remoções populacionais forçadas, crises de refugiados, guerras civis e massacres étnicos que se desenrolaram pelo restante da década de 1940.

\footnotetext{
* Mestre em Ciências Sociais pela Universidade Estadual Paulista Júlio de Mesquita Filho (Faculdade de Filosofia e Ciências de Marília),E-mail: felipedesouza1988@gmail.com
}

(cc) EY Direito autoral e licença de uso: Este artigo está licenciado sob uma Licença Creative Commons. Com essa licença você pode compartilhar, adaptar, para qualquer fim, desde que atribua a autoria da obra, forneça um link para a licença, e indicar se foram feitas alterações. 
O mito da união foi particularmente forte entre os países que estiveram sob ocupação nazista durante a guerra, dos quais a França é o exemplo mais conhecido. A odeoa da união foi essencial tanto para encorajar a resistência quanto para, no final da guerra, legitimar as forças políticas que viriam a se tornar dominantes - o general De Gaulle, por exemplo, se amparou fortemente na ideia de um povo francês coeso sob sua liderança, lutando simultaneamente contra os alemães e contra a minúscula república de Vichy. Lowe nos mostra, por outro lado, que o colaboracionismo foi muito maior do que se costuma admitir e, terminada a guerra, membros da resistência e colaboradores se engalfinharam em ondas de ataques mútuos, emboscadas, assassinatos e degradação pública ${ }^{1}$. Tais como as cisões políticas, os conflitos étnicos continuaram a fazer vítimas no pós-guerra, especialmente no Leste Europeu. Tchecos, poloneses, ucranianos, húngaros e romenos, entre outros, foram simultaneamente vítimas e agentes de pogroms, agressões e assassinatos aleatórios e internamentos em campos de prisioneiros e remoções forçadas. As mudanças nas demarcações fronteiriças entre vários países, determinadas no pós-guerra, acabou por transformar grandes grupos de indivíduos em minorias étnicas em países estrangeiros, sujeitos a toda sorte de maus tratos, com a conivência ou encorajamento claro dos frágeis novos governos. Em junho de 1945, por exemplo, o Comitê Nacional Local de Praga distribuiu cartazes explanando a forma como seriam tratados os alemães, húngaros $\mathrm{e}$ colaboracionistas dentro do território tchecoslováco. Eles deveriam usar uma faixa no braço esquerdo com a imagem de uma suástica, e foram proibidos de utilizar o transporte público, caminhar pelas calçadas e permanecer nas ruas após as 20h, entre várias outras restrições. Os alemães — pouco importando se fossem soldados ou cidadãos comuns - estiveram entre os grupos mais atingidos pelos atos de desforra nos países libertos da ocupação do III Reich. Na Polônia, tornou-se comum que alemães fossem cercados por populares e tivessem suásticas cravadas à navalha em seus braços e testas, ou que fossem estrangulados em postes de iluminação.

Atos como esse ocorreram em toda a Europa. São quase surreais os relatos de canibalismo, famílias famintas vagando sem rumo por estradas destruídas, soldados búlgaros jogando futebol com cabeças decepadas de prisioneiros gregos, nazistas em fuga esmagando a cabeça de bebês judeus contra o solo e guerrilheiros ucranianos torturando mulheres polonesas com instrumentos agrícolas. Somando-se ao caos e à violência, havia uma dificuldade imensa de acesso a informações fidedignas e de clivar os boatos dos fatos reais. Por isso, uma pesquisa acerca desse tema poderia facilmente perder o rigor e adotar tons sensacionalistas, mas Lowe consegue evitar esses riscos. O autor se ampara em uma ampla gama de fontes primárias - com destaque para documentos oficiais liberados depois da dissolução do bloco socialista e para depoimentos de sobreviventes da época, compilados por projetos de 
história oral empreendidos por alguns museus europeus - , e em todo o livro fica patente a habilidade no trato com as fontes. Lowe evita ao máximo utilizar afirmações demasiadamente taxativas, e cruza os dados, estatísticas e relatos, sempre deixando claras as eventuais incongruências, inverossimilhanças e os pontos que carecem de maior comprovação documental.

Essa problematização das fontes se faz especialmente importante quando se tem em mente que os fatos tratados no livro ainda hoje são manipulados em disputas políticas. Certos grupos de direita franceses, por exemplo, tentam mitigar seu passado como colaboradores da ocupação ao mesmo tempo em que retratam a Resistência como um grupo de fanáticos que massacravam inocentes. Começaram a circular, na imprensa popular francesa da década de 1950, inúmeros relatos duvidosos acerca de atos de tortura e chacinas cometidos pela esquerda, e, posteriormente, muitos escritores passaram a afirmar que mais de 100 mil colaboradores foram executados pela Resistência nos meses após a liberação. Lowe aponta que não há evidências que confirmem esse número: dados fornecidos por agências governamentais francesas e estudos recentes indicam que não houve mais do que dez mil execuções durante o período em questão.

É justamente por conta do trato cuidadoso com os documentos que causa estranhamento a abordagem de Lowe das ações do governo soviético e seus aliados políticos no Leste Europeu. A Europa Oriental sofreu um nível de destruição maior do que as regiões ocidentais, devido ao projeto hitleriano de colonização e escravização dos povos eslavos, o que fez com que os movimentos alemães iniciados na Operaçao Barbarossa (junho de 1941) fossem particularmente brutais. Grande parte do livro se ocupa dessa parte do continente, e Lowe narra com detalhes as atrocidades cometidas pelo Exército Vermelho em sua vitória contra a Wehrmacht na rota entre Stalingrado e Berlim - estupros em massa de mulheres alemãs, torturas, incêndio de vilas e massacres - , bem como os métodos violentos pelos quais o Kremlin assistiu o estabelecimento de regimes aliados. Esses processos estão bem documentados e já foram analisados por inúmeros historiadores sérios. Todavia, o problema da abordagem de Lowe reside na falta de contextualização da construção de uma "zona tampão" pró-Moscou entre a URSS e os países capitalistas. Em sua narrativa, a URSS aparece como um estado nacional movido pela expansão territorial como um fim em si mesmo e pela difusão ideológica do "marxismo" stalinista a qualquer custo, enquando os Aliados ocidentais - EUA e Inglaterra - são vistos, por comparação, como forças que prezavam fundamentalmente pela liberdade e pela justiça, a despeito de lapsos infelizes. Em certa passagem, ao narrar o golpe de estado que instaurou o Partido Comunista no governo da Romênia, Lowe afirma que "[...] a ameaça contra o Ocidente era muito real. A despeito de sua mão pesada e da abordagem muitas vezes inadequada, os governos do Ocidente 
realmente acreditavam que seguiam o caminho menos ruim"2. Em seguida, complementa:

\begin{abstract}
Em uma escolha direta entre o comunismo stalinista e a mistura imperfeita de democracia adotada pelo Ocidente, a última era sem dúvida o menor de dois males. Os comunistas no Leste Europeu exibiram uma falta de misericórdia em sua busca pelo poder que fez com que os governos ocidentais parecessem amadores incompetentes. ${ }^{3}$
\end{abstract}

Essas colocações são muito problemáticas. Nem de passagem é abordado o fato amplamente conhecido que o governo de Stalin não tinha intenção nem condições de empreender qualquer tipo de ameaça contra o "Ocidente". Também não é dito que o estabelecimento de uma esfera de influência soviética tinha muito a ver com a estratégia de dificultar possíveis ataques futuros à URSS por parte dos países capitalistas, em especial dos EUA, que justamente no desfecho da Segunda Guerra Mundial se firmava como a potência líder do mundo capitalista. Nesse sentido, a análise de Lowe parece se alinhar à visão da historiografia ortodoxa sobre a Guerra Fria, segundo a qual, em consonância com a visão dominante na diplomacia estadunidense da segunda metade da década de 1940, esse conflito teria sido iniciado unilateralmente pela ameaça soviética, contra a qual as democracias ocidentais teriam sido obrigadas a agir. Tal interpretação vem sendo consistentemente contestada pela linha revisionista desde o final dos anos 1950.

Essa abordagem simplista se destaca negativamente em um livro que pretende questionar o modo tradicional e esquemático de se compreender os efeitos da Segunda Guerra Mundial, e que afirma que "em um continente grande e diverso como a Europa, é sempre imprudente generalizar". ${ }^{4}$ Tal objetivo é alcançado com maior sucesso quando Lowe se detém nas especificidades de cada região: aborda-se, por exemplo, o processo pelo qual os comunistas foram antidemocraticamente excluídos dos governos italiano e francês logo após 1945, o apoio britânico às violentas forças conservadoras durante a guerra civil grega (1946-1949) e — o ponto alto do livro — as centenárias tensões étnicas e religiosas da Iugoslávia, que se imbricaram complexamente com questões políticas mais recentes. Quando o livro se propõe a análises geopolíticas mais amplas, o resultado é menos do que satisfatório.

Desde o debacle do chamado socialismo real e com o crescimento de vários partidos de direita na Europa, tem-se aumentado a tentativa de resgate de alguns episódios e personagens do período do imediato pós-guerra. Lowe afirma que na Hungria, Croácia, Ucrânia e países bálticos, indivíduos conhecidos por seu ultranacionalismo, antissemitismo e violência vêm sendo reabilitados, por alguns grupos, como heróis nacionais. Na Itália, tem-se assistido, nos últimos anos, à popularização de certa historiografia conservadora, que distorce os 
dados para relativizar os crimes do fascismo e simultaneamente retratar os partisans italianos como pouco mais do que um bando de assassinos. Frente a esse quadro, a importância da pesquisa de Lowe reside não apenas em sua interpretação séria do período em foco, mas também em possibilitar o início de uma compreensão mais apurada sobre o tempo presente. Afinal, a disputa pela memória da Segunda Guerra Mundial e seu epílogo faz parte das tensões políticas da Europa neste início de século XXI.

\section{Notas}

1 A respeito desse contexto, foram muitos discutidos os rituais de humilhação que sofriam as chamadas "colaboradoras verticais", mulheres que haviam se relacionado sexualmente com soldados alemães, especialmente na França: eram agredidas pelos seus concidadãos nas ruas e tinham os cabelos raspados.

2 LOWE, Keith. Continente selvagem: o caos na Europa depois da Segunda Guerra Mundial. Tradução de Rachel Botelho e Paulo Schiller. -1.ed.- Rio de Janeiro: Zahar, 2017, p.353.

3 Idem.

4 Ibidem, p.402.

Recebido em 01/06/2017

Aprovado em 08/09/2017 